DIW BERLIN

Discussion

Papers
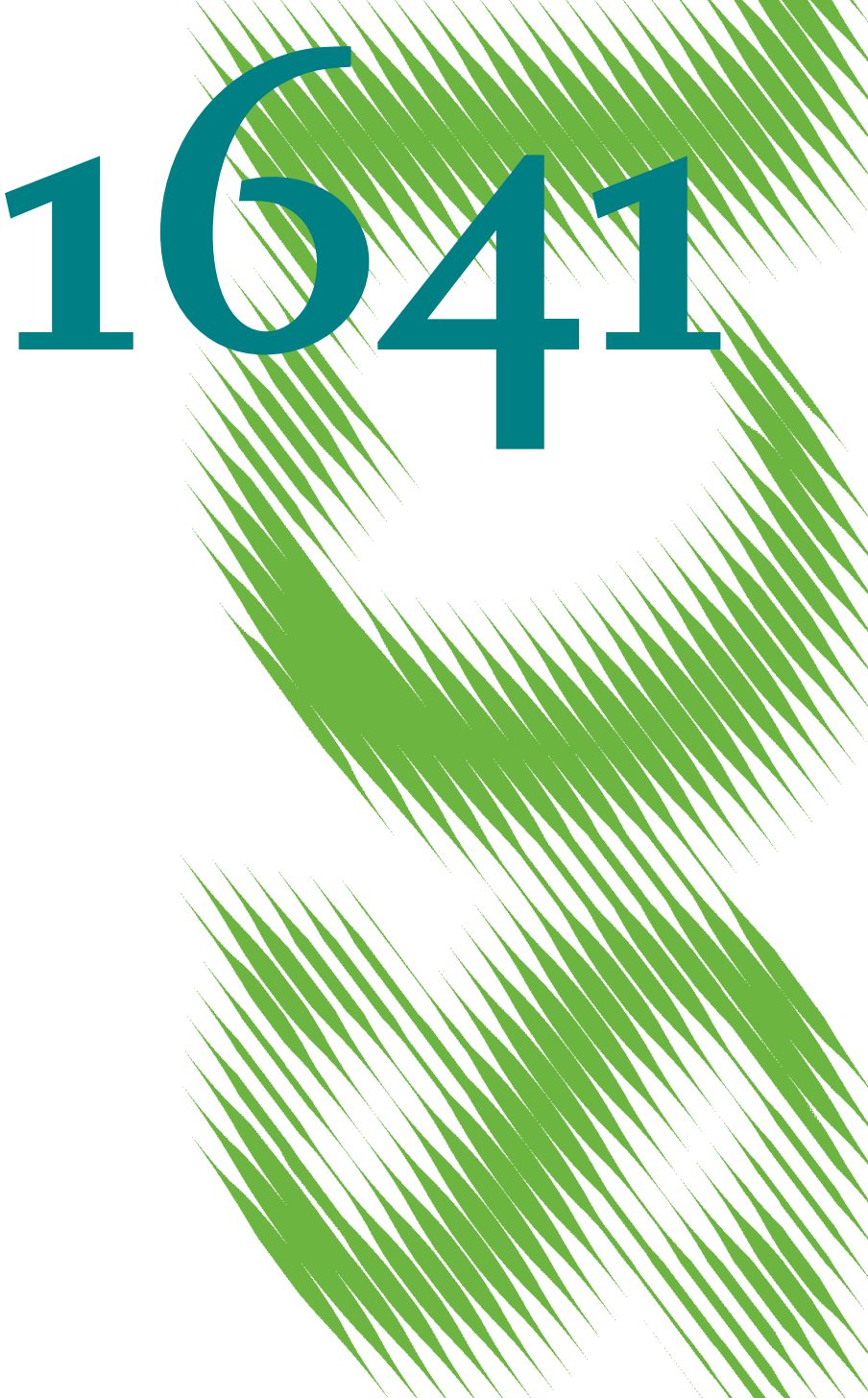

Productive Efficiency and Ownership When Market Restructuring Affects Production Technologies 
Opinions expressed in this paper are those of the author(s) and do not necessarily reflect views of the institute.

IMPRESSUM

(C) DIW Berlin, 2017

DIW Berlin

German Institute for Economic Research

Mohrenstr. 58

10117 Berlin

Tel. +49 (30) $89789-0$

Fax +49 (30) $89789-200$

http://www.diw.de

ISSN electronic edition 1619-4535

Papers can be downloaded free of charge from the DIW Berlin website:

http://www.diw.de/discussionpapers

Discussion Papers of DIW Berlin are indexed in RePEc and SSRN:

http://ideas.repec.org/s/diw/diwwpp.html

http://www.ssrn.com/link/DIW-Berlin-German-Inst-Econ-Res.html 


\title{
Productive Efficiency and Ownership When Market Restructuring Affects Production Technologies
}

\author{
Astrid Cullmann * $\quad$ Maria Nieswand ${ }^{\dagger} \quad$ Julia Rechlitz ${ }^{\ddagger}$ \\ January 2017
}

\begin{abstract}
While the link between the ownership and productive efficiency of firms has been discussed extensively, no consensus exists regarding the superiority of one or the other in non-competitive, regulated environments. This paper applies a flexible production model to test for efficiency differences associated with ownership types while allowing the production to adapt to market restructuring over time. Our empirical setting is based on a new, rich micro dataset of electricity distribution firms operating between 2006 and 2012 in Germany, where the energy transition enforces the adjustment of energy infrastructure. First, our results show that electricity distribution system operators adapted their production technologies over time. Second, there is no empirical evidence that public firms operated any less efficiently than private firms. The empirical findings are relevant to the (re)municipalization debate, which appears to have exaggerated the dichotomy between public and private utilities' efficiency.
\end{abstract}

JEL-Classification: L94, L51, L98

Keywords: Utilities, Ownership, Productivity, Electricity Distribution, Energiewende

${ }^{*}$ Corresponding author. Dr. Astrid Cullmann, DIW Berlin - German Institute for Economic Research, Department of Firms and Markets, Mohrenstrasse 58, D-10117 Berlin, Germany; phone: +4930-89789-678, email: acullmann@diw.de

${ }^{\dagger}$ Dr. Maria Nieswand, DIW Berlin - German Institute for Economic Research, Department of Firms and Markets, Mohrenstrasse 58, D-10117 Berlin, Germany; phone: +49-30-89789-224, email: mnieswand@diw.de

${ }^{\ddagger}$ Julia Rechlitz, DIW Berlin - German Institute for Economic Research, Department of Energy, Transportation, Environment, Mohrenstrasse 58, D-10117 Berlin, Germany; phone: +49-30-89789-467, email: jrechlitz@diw.de 


\section{Introduction}

The debate on private versus state ownership and efficiency of firms has not yet reached a conclusion. On the one hand, arguments based on property rights, public choice, and agency theory provide multiple rationales for the economic superiority of private firms in terms of productive efficiency. On the other hand, the performance of privately and state-owned firms ${ }^{1}$ should be the same in regulated environments, at least under complete regulatory contracts (Laffont and Tirole, 1993). Uncertainties regarding the performance differences between privately and publicly owned firms are particularly evident in the recent intensive debates on (re)municipalization in infrastructure industries such as the energy sector. ${ }^{2}$ Much of the relevant empirical literature on public infrastructure industries report no statistically significant differences in productivity or production costs between public and private firms (Atkinson and Halvorsen, 1986), yet some studies show that private firms outperform publicly owned ones (Kumbhakar and Hjalmarsson, 1998). Still other studies emphasize that public firms operating electricity grids achieve a higher level of efficiency (Kwoka, 2005).

Variations in the empirical studies are mainly attributed to sample characteristics, the modeling techniques used, and the difficulties in disentangling the sources of productive efficiency. Moreover, structural changes that affect production technologies challenge the performance evaluation. The energy sector is a prominent example of the extensive transformation required to build a low-carbon energy system. Hence, in empirically investigating the productive efficiency of distribution networks, the challenge is how to account for changes in the production technology caused by sectoral restructuring.

To our knowledge, this paper is the first empirical study of the efficiency differences between private and public electricity distribution companies (DSOs) that allows for timevarying technologies and firm-specific technology adaption. We propose a semiparametric production model and use flexible techniques according to Sun et al. (2015) to estimate productive efficiency where the coefficients of the function can vary over time. Thus, we explicitly allow for heterogeneous technologies over time without making assumptions about how the time trend influences the coefficients. We measure productive efficiency based on an input distance function (IDF), instead of estimating a cost function. ${ }^{3}$

We apply our framework to the German electricity sector for the period 2006 to 2012 and

\footnotetext{
${ }^{1}$ We use the terms state-owned and public firms interchangeably and emphasize that public ownership does not relate to firms listed on a stock exchange.

${ }^{2}$ The term (re)municipalization refers to buying back previously privatized firms, the increase of public shares in firms, and the new foundation of state-owned firms.

${ }^{3}$ When input ratios can be assumed to be exogenous, and additionally due to duality this approach is economically meaningful and does not require information on input prices (Färe and Primont, 1995; Das and Kumbhakar, 2012).
} 
use new micro data on German electricity distribution system operators. Germany is an ideal empirical setting for our purpose. The country, which occupies a prominent position in Europe's transition to a decentralized low-carbon energy system, has adopted one of the most ambitious energy transition programs in the world. Thus, our approach and results are also relevant for countries considering less carbon-intensive energy networks. Further, interest in the performance capabilities of different ownership types is extremely high as local governments have begun to reinforce economic activities by re-purchasing privatized firms (also referred to as deprivatization or remunicipalization). Another feature is Germany's intense policy debate, particularly since the competition authorities, the German Monopolies Commission and the Bundeskartellamt, BKartA, have adopted a critical attitude towards remunicipalization.

Our empirical findings show that both publicly and privately owned distribution firms have adapted their production technology to restructuring. For both types of ownership, productive efficiency slightly increases during the time period. Our results do not support any efficiency differences between public and private firms. Various robustness checks confirm our findings.

The remainder of this paper is structured as follows: Section 2 surveys the relevant literature; section 3 describes the German situation; section 4 introduces the data set and defines the variables; section 5 presents the empirical model and estimation strategy; section 6 discusses the empirical findings and presents robustness checks, finally section 7 concludes.

\section{Related Literature}

\subsection{Theoretical literature}

Studies of the ownership-performance link encompass agency theory, property rights, and public choice, which all provide different rationales for the superiority of private firms due to the differences in objectives, incentives, and control mechanisms. ${ }^{4}$ For example, agency theory assumes that private firms are better able to handle the principal-agent dilemma. Agents (managers) seek to maximize their own utility rather than that of the whole firm or its principals (owners), and consequently are more likely to achieve a lower efficiency level. Considering property rights, Alchian and Demsetz (1973) and Demsetz (1967) suggest that public ownership attenuates property rights, thus reducing the incentives to minimize costs. Property rights theory also postulates that potential divergences of interests between private firms' owners and managers are further reduced by external mechanisms,

\footnotetext{
${ }^{4}$ See Megginson (2001) for a detailed literature overview.
} 
such as a market for ownership rights that enables owners to sell their shares if they are dissatisfied with managerial performance, the threat of takeover, or bankruptcy, or an extensive managerial labor market. The public choice literature, particularly the theory of bureaucracy (Shleifer and Vishny, 1994) assumes that politicians impose their objectives on public organizations in order to gain votes, and that these objectives may be at odds with profit maximization and, consequently, harm efficiency (Villalonga, 2000). For example, in some public firms, an inefficiently high labor share has been observed to decrease unemployment (Shleifer and Vishny, 1994).

Understanding the environment in which firms operate is an important factor in the private versus public ownership and performance debate (Bartel and Harrison, 2005). In competitive markets firms are forced to set prices close to marginal costs and provide owners with information on costs and managerial effort, ${ }^{5}$ whereas in a regulated environment the incentive effect as well as the information effect are diminished. ${ }^{6}$ Under complete regulatory contracts, the outcome of private and public firms should be the same. $^{7}$

Electricity distribution exhibits the characteristics of typical natural monopolies. In this context Leibenstein (1966) derives the theory of X-inefficency and argues that regulated monopolies in general are likely to be inefficient regardless of ownership. ${ }^{8}$ Button and Weyman-Jones (1994) relate the theory of X-inefficiency to the measurement of inefficiency by means of both parametric and nonparametric efficiency analysis.

\subsection{Empircal studies}

The majority of empirical studies on performance differences according to different ownership structure in the electricity sector have focused on utilities operating from the 1960s to the 1990s in the United States. In general, the conclusions drawn about the performance differences between public and private firms during this period are rather weak, in part due to small sample sizes, overly restrictive assumptions, and failing to account for

\footnotetext{
${ }^{5}$ Further, owners can create incentives for management to reduce the asymmetric information closing the managerial slack (Hart, 1983; Shirley and Walsh, 2001).

${ }^{6}$ The incentive effect is mainly driven by managerial concern over losing market share due to inefficient performance. Information effect refers to the principal-agent relationship between owners and managers, and hence, becomes more important by assuming a situation of separated ownership and management (Leibenstein, 1966).

${ }^{7}$ Laffont and Tirole (1993) show that the superiority of private versus public firms depends on the contract setting the provision of the goods or services of a regulated monopoly. Laffont and Tirole (1991) show that the implementation of a regulator produces a more complex principal-agent relationship because private firms now have two principals (the regulator and the owner) who may have opposing objectives. This does not apply to publicly owned firms, since their model assumes that the political objectives of the regulator and the public owner are well matched.

${ }^{8}$ Leibenstein (1966) shows that economic agents may not achieve maximal efficiency in their productive decisions and behavior.
} 
the impact of market structure, regulation, and vertical integration (Peters, 1993; Pollitt, 1995; Atkinson and Halvorsen, 1986).

Early studies also use different estimation methods; topics include managers' turnover rates (De Alessi, 1974), price discrimination (Peltzman, 1971), investment behavior (Rose and Joskow, 1990), and cost efficiency (Neuberg, 1977). A more recent study by Kwoka (2005) using cross-sectional data from 1989 on cost efficiency finds cost advantages for public firms in electricity distribution, but cost advantages for private firms in electricity generation. Boylan (2016) who investigates DSOs' investment behavior in order to prevent outages due to storms finds that publicly owned firms spend more on maintaining their distribution lines, but better storm preparedness does not necessarily follow.

Studies of the EU's power markets are scarce, partly due to the absence of data. Kumbhakar and Hjalmarsson (1998) conclude that private distributors in Sweden are relatively more cost efficient. Borghi et al. (2016) analyse the impact of ownership and governance quality on total factor productivity for DSOs in $16 \mathrm{EU}$ countries. Not accounting for technology adaptions due to market restructuring they find that depending on the quality of the institutional framework publicly owned firms exhibit a higher/lower level of productivity compared to privately owned ones. For Germany they find no significant difference in productivity between the two ownership types. Despite the attention that economic theory attributes to alleged performance differences between public and private firms, the empirical evidence for the electricity sector, an important sector of public involvement in Europe, is rare.

In summary, meta-surveys summarize the empirical evidence on performance differences between state-owned and private firms across countries and sectors, (see e.g., Megginson, 2001; Vining and Boardman, 1992) but neglect any differences in regulation, market structure and firms across industries, countries, and time. None of the empirical papers account for the restructuring processes needed to implement a different energy system or the sector's flexible production functions.

\section{The German Electricity Sector}

\subsection{Liberalization, regulation and energy transition}

Germany's electricity sector has undergone intense transition and restructuring since 1998 when the sector was liberalized. Prior to 1998, electricity was supplied by more than 800 local, mostly small monopolies that were vertically and horizontally integrated. Most offered other products, such as natural gas supply and district heating. EU Directives 96/92/EC and 2003/54/EC, which initiated the European electricity sector's reorgani- 
zation, envisioned a gradual opening of end-consumer markets until 2007. ${ }^{9}$ In 2005, Germany's regulatory authority was put in charge of supervising the German electricity sector. Centralized regulation and unbundling reforms ${ }^{10}$ in 2007 significantly reduced discrimination in network access for third parties.

In addition to the liberalization and regulation efforts, Germany's energy transition (Energiewende) $)^{11}$ to a low-carbon energy system, requires structural changes in its energy sector. Continued integration of renewable energy sources has led to a fundamental transformation of the power system that affects both Germany's power plant fleet and the transmission and distribution grids. This development has been supported by German legislation, e.g., in 1991, the first electricity feed-in tariff was enacted to support the expansion of renewables. Its revision during the 1990s resulted in the German Renewable Energy Sources Act (EEG), which became effective in 2000. Including higher and technology-specific remuneration tariffs, investments in renewables have gained momentum. In addition to large wind parks and hydro plants also small scale renewable power plants became profitable (Brüggemeier, 2015). Germany's development of the installed capacities of renewables demonstrates the success of supporting them: renewable capacity rose from 4.2 GW in 1990 to $97.1 \mathrm{GW}$ in 2015 (Bundesministerium für Wirtschaft und Energie, 2016).

Germany's DSOs adapted to the Energiewende because they were obligated to accept steadily increasing amounts of renewable power from the growing number of small decentralized sources rather than large generating plants. Stochastic weather conditions, e.g., for wind and solar, which make quantities unpredictable and cause a supply and demand mismatch and reversed load flows forced grid operators to change their investment and network expansion strategies and modes of operation (Deutsche Energie-Agentur, 2012). The need for the electricity supply infrastructure to adapt was recognized in the second amendment to the EEG in 2009. It obliges DSOs to invest, strengthen and optimize networks to cope with large share of fluctuating renewables. ${ }^{12}$ While DSOs' investments and expenses varied between 5,108 and 5,752 million Euro between 2007 and 2009, a significant increase can be observed in the time period between 2010 and 2012 reaching

\footnotetext{
${ }^{9}$ Contrary to France and Italy, the German government decided to liberalize supply to all consumers classes (large industrial, businesses, residential consumers) in 1998. Full competition, however, in particular for residential customers, took some time to develop.

${ }^{10}$ These reforms imposed the legal separation of the distribution networks with the typical characteristics of a natural monopoly from the generation and retail segments of integrated companies with more than 100,000 customers.

${ }^{11}$ The energy transition launched in the 1990s, after controversial political discussions in the early stages, gained broad political consensus. Its major objectives are to combat climate change and to reduce greenhouse gas emissions. By 2050 renewable energy must account for at least 80 percent of Germany's electricity consumption. Germany has taken a leading role internationally, e.g.,the Paris Agreement negotiated at the 2015 United Nations Climate Change Conference (COP 21).

${ }^{12}$ See article 9(1) EEG.
} 
its maximum in 2011 with investments and expenses of 6,930 million Euro (Bundesnetzagentur, 2014). Also the number of DSOs adapting their networks to handle the increasing share of renewables according to article 9(1) EEG steadily increased from 2009 to $2012 .^{13}$

\subsection{German DSO ownership}

The expiration of numerous concession contracts for distribution grids gave local public authorities the opportunity to decide whether to renew existing contracts, grant the concession to third parties, or reverse the privatization. ${ }^{14}$

In the 1990s, many public authorities divested their shares in electricity distribution firms. Too often, however, deregulation and privatization have failed to realize the expected cost savings for producers and price reductions for consumers. In response to this observation and income seeking, municipal governments have recently begun to reinforce economic activities by re-purchasing privatized firms, by increasing their shares of ownership in partially privatized firms, or by establishing new publicly owned firms. Besides local public authorities have the aim to increase their public influence to implement ecological, socio-economic and fiscal objectives, and receive at the same time an intense support form the local population. ${ }^{15}$

The rising economic activities of the public sector in the electricity sector combined with citizens' concerns about the environment intensified the larger policy debate. The competition authorities, the German Monopolies Commission and the BKartA, adopted a critical attitude towards remunicipalization. They found no sufficient reasons for an expansion of the public sector and even feared a decreasing efficiency of Germany's publicly owned utilities (Monopolkommission, 2014).

\footnotetext{
${ }^{13}$ There is a distinction between measures optimizing the grid, grid reinforcement, and grid expansion. The number of DSOs which undertook grid optimization rose from 112 in 2009 to 404 in 2012 . DSOs undertaking reinforcement and grid expansion rose from 147 to 438 and 189 to 413, respectively between 2009 and 2012 (Bundesnetzagentur, 2014).

${ }^{14}$ About 8,000 of 14,000 concessions in the electricity sector expired between 2010 and 2015 (Berlo and Wagner, 2013).

${ }^{15}$ Hamburg and Berlin are two prominent examples. Recent efforts in these large cities to take over the utilities had a major impact on the public. After acquiring 25.1 percent of the shares in local energy, gas, and district heating utilities in 2012, Hamburg took over the entire electricity distribution network in 2014 and negotiated a repurchase option with the previous owner, Vattenfall, for the district heating networks (Monopolkommission, 2014). In Berlin, although a 2013 referendum for the repurchase of the electricity distribution network failed, on March 14, 2016, the state-owned company Berlin Energie submitted a proposal for a complete buyback (Berlin Energie, 2016). Similar actions have been observed elsewhere and in other energy sectors. The number of public electricity network operatore increased by 11 percent (Berlo and Wagner, 2013).
} 
Table 1: Sample size

\begin{tabular}{lllllllll}
\hline Year & 2006 & 2007 & 2008 & 2009 & 2010 & 2011 & 2012 & Sum \\
\hline Number of observations & 179 & 225 & 280 & 306 & 311 & 293 & 303 & 1897 \\
\hline Public ownership & 155 & 187 & 237 & 264 & 263 & 245 & 260 & 1611 \\
Private ownership & 24 & 38 & 43 & 42 & 48 & 48 & 43 & 286 \\
\hline \hline
\end{tabular}

\section{Dataset and Definitions of Variables}

Our analysis is based on two data sources: a new and rich panel data set of firm-specific micro data provided by the German Federal Statistical Office (FDZ) and the physical network characteristics provided by the German data service provider ene't. The FDZ data include various cost components, output, revenue structures, labor input, and other variables related to the production process. It comprises how many German utilities have more than ten employees which provide electricity, natural gas, district heating, water supply, sewerage, and waste treatment. The utilities have different degrees of vertical and horizontal integration. We use a subsample of electricity distribution companies from 2006 on when most required unbundling was completed. The ene't data include physical information about the distribution networks, grid-specific network charges and other levies, and characteristic attributes of the municipalities served. Merging the two data sets and cleaning the data obtains an unbalanced panel of 1897 observations from 2006 to 2012. ${ }^{16}$ Table 1 lists the number of observations for each year.

To assess productive efficiency, we use firms' production data, because the data on physical inputs and outputs are generally reliable, readily available, and well defined. ${ }^{17}$ To model the production process, we use the output and input variables and the exogenous factors derived from the empirical literature on efficiency analysis of electricity distribution companies (see Cullmann, 2010; Jamasb and Pollitt, 2000).

A DSO's common outputs are number of customers served $\left(y_{C}\right)$ measured by total number of connected customers summed up over all voltage levels ${ }^{18}$ and annual amount of distributed electricity $\left(y_{E}\right)$, i.e., total annual amount of electricity distributed through the grid over all voltage levels. The common input factors are labor $\left(x_{L}\right)$, given by the annual amount of hours worked, and grid length $\left(x_{N}\right)$ as capital input, i.e., line length

\footnotetext{
${ }^{16}$ From 2007 on, the data represent 40 to 60 percent of actual electricity consumption by residential, trade, commerce, and service users (Arbeitsgemeinschaft Energiebilanzen, 2016).

${ }^{17}$ Further, input price data is not available and requires constructing proxies from further data sources.

${ }^{18}$ The actual measure counts the points of withdrawal. For convenience, we name the variable customers. The points of withdrawal can be interpreted as the lower bound of the actual number of customers because multiple households can be linked to one point of withdrawal. More detailed information is absent.
} 
Table 2: Definitions of variables

\begin{tabular}{llll}
\hline Variable & Name & Type & Definition and unit of measurement \\
\hline$y_{C}$ & customers & output variable & number of customers in thousands \\
$y_{E}$ & electricity & output variable & electricity distributed in MWh \\
$x_{N}$ & network & input variable & grid length in km \\
$x_{L}$ & labor & input variable & amount of hours worked in hours \\
$z_{D}$ & density & exogenous factor & customer density in km ${ }^{2}$ \\
$z_{O}$ & overhead & exogenous factor & share of overhead lines in percent \\
own & ownership & & dummy variable \\
\hline \hline
\end{tabular}

summed up over all voltage levels and line types (underground cable and overhead lines). Two exogenous factors control for observed heterogeneity between firms: density $\left(z_{D}\right)$ is computed as the ratio of customers and the area served, and $z_{O}$ captures the share of the length of overhead lines to the length of the complete distribution grid. A dummy variable (own) representing ownership takes the value of one if the firm is publicly owned with more than a 50 percent share in nominal capital and zero otherwise,

$$
\text { own }= \begin{cases}1 & \text { if firm publicly owned } \\ 0 & \text { otherwise, privately owned }\end{cases}
$$

Table 2 describes the selected variables and Table 3 lists the summary statistics by ownership type. From the statistics, the large variance between observations becomes clear. For example, 25 percent of state-owned firms serve less than 8 million customers, whereas the upper quarter serves more than 37 million customers. In the case of private firms, 25 percent of the firms serve less than 2.9 and more than 72.6 million customers, respectively. While the median values of $y_{C}, x_{L}$, and $z_{D}$ are smaller for private firms compared to publicly owned firms, the median values of $y_{E}, x_{N}$, and $z_{O}$ are larger. Hence, the data set does not appear to be subject to the systematic differences existing between privately and publicly owned firms.

\section{Estimating Productive Efficiency with Time Varying Production Technology}

We build our production model on the input distance function representation of the transformation function (see Kumbhakar and Sun, 2012) which is able to model multi-output production in opposition to a single output production function. ${ }^{19}$ The transformation

\footnotetext{
${ }^{19}$ One can derive all of the primal formulations from a transformation function by using different normalizing (identifying) restrictions (Kumbhakar and Sun, 2012).
} 
Table 3: Summary statistics of the variables

\begin{tabular}{lllrrrrr}
\hline Variable & Name & Type & $25 \%$ Quart. & Median & Mean & $75 \%$ Quart. & Std. Dev. \\
\hline$y_{C}$ & \multirow{2}{*}{ customers } & public & 7,996 & 15,707 & 25,572 & 26,776 & 36,998 \\
& & private & 2,889 & 14,361 & 45,906 & 44,176 & 72,686 \\
$y_{E}$ & electricity & public & 96,729 & 192,643 & 432,171 & 372,441 & $1,158,509$ \\
& & private & 40,624 & 240,329 & $1,033,875$ & 891,961 & $2,158,137$ \\
$x_{N}$ & \multirow{2}{*}{ network } & public & 253 & 431 & 674 & 732 & 928 \\
& & private & 183 & 519 & 1,676 & 1,426 & 2,788 \\
$x_{L}$ & \multirow{2}{*}{ labor } & public & 47,672 & 94,241 & 133,304 & 163,870 & 141,701 \\
& & private & 8,098 & 22,329 & 91,693 & 108,181 & 163,029 \\
$z_{D}$ & \multirow{2}{*}{ density } & public & 486 & 1,062 & 1,165 & 1,670 & 814 \\
& & private & 466 & 833 & 1,085 & 1,509 & 896 \\
$z_{O}$ & \multirow{2}{*}{ overhead } & public & 0.02 & 0.06 & 0.08 & 0.12 & 0.08 \\
& & private & 0.04 & 0.12 & 0.20 & 0.32 & 0.21 \\
\hline \hline
\end{tabular}

function is given by $A * T(X, Y, Z, t)=1$, where $X$ is a vector of $P$ different inputs, $Y$ is a vector of $Q$ different outputs, $Z$ a vector of $K$ different exogenous factors, and $t$ is the time trend. $T()$ is the transformation function. Our assumption that $T()$ is homogeneous of degree 1 in $X$ obtains the input distance function ${ }^{20} x_{1}^{-1}=\Lambda * H(\tilde{X}, Y, Z, t)$, where $x_{1}$ is the numeraire input and $\tilde{X}$ is a vector of input ratios, with $\tilde{x}_{p}=x_{p} / x_{1}, p=2, \ldots, P$. IDFs are extensively used for modeling inefficiency (Kumbhakar and Sun, 2012), especially in regulated network infrastructure industries. To analyze efficiency within the electricity distribution sector the input distance function formulation is economically appropriate, because the inputs are endogenous and the outputs (electricity distributed; number of customers/connections) are exogenous for the firms in this sector. ${ }^{21}$ Furthermore, DSOs minimize cost to produce the exogenously given (determined by demand) output. ${ }^{22}$

In the general form, the IDF in logs is given by

$$
-\ln x_{1, i t}=\theta+\phi^{\prime} \ln B_{i t}+v_{i t}
$$

where $\ln x_{1, i t}$ is the numeraire input for firm $i$ in year $t$ in logs, $\theta$ is the intercept, and $B_{i t}=[\tilde{X}, Y, Z]$ is a matrix of covariates including $p=2, \ldots, P$ input ratios, $q=1, \ldots, Q$ outputs, and $k=1, \ldots, K$ exogenous factors. $v_{i t}$ is a noise term and $\phi$ is the slope

\footnotetext{
${ }^{20}$ This coincides with the input distance function as a representation of a technology introduced by Shephard (1953).

${ }^{21}$ The firms are legally obliged to connect and serve all customers. This is stated in the Energy Economy Law (EnWG).

${ }^{22}$ Das and Kumbhakar (2012) show that input ratios are exogenous under cost minimization. Färe and Primont (1995) show that the input distance function is dual to the cost function; hence, the input distance function is ideal to use when input prices are not available or do not vary much. Duality also means that input coefficients are equal to the cost shares and that output coefficients equal to the negative cost elasticities.
} 
coefficient vector.

To model the restructuring and transformation process in the production technology, we allow the technology parameters to vary over time. Additionally, the intercept varies over firms to capture firm fixed effects. Hence, $\theta$ is an unknown function of time and firm effects while $\phi$ is an unknown function of $t$ such that

$$
-\ln x_{1, i t}=\theta(i, t)+\phi^{\prime}(t) \ln B_{i t}+v_{i t}
$$

The IDF has the same shape for all firms in time period $t$ and is semi-parametric, because it is of some functional form that needs to be specified, but the coefficients are nonparametric functions of $t$. Hence, there is no a priori assumption on how time affects the shape of the input distance function.

We measure firm-specific productive efficiency within the frontier concept ${ }^{23}$ where a technology frontier is determined by the most efficient firms, i.e. firms using the lowest input quantities to produce a given output. Firms that span the frontier are considered productively efficient. Deviations from that frontier can occur due to firm fixed effects, inefficiency and noise. To construct a yearly frontier technology, we define

$$
\theta(i, t)=\alpha(t)+m_{i t}
$$

with

$$
\alpha(t)=\max _{i}\{\theta(i, t)\}
$$

Given that $\alpha(t)$ is the largest intercept $\theta(i, t)$ among the firms in period $t, m_{i t}$ can be interpreted as some time and firm-specific distance to a yearly frontier technology. Since $m$ depends on $i$ and $t$, it captures the time and firm-specific effects, that can be caused by the fixed effects $\mu_{i}$, transient inefficiency, $u_{i t}$, and persistent inefficiency $\eta_{i}$.

Hence, for the IDF specified in $(3), m_{i t}$ is defined by

$$
m_{i t}=\mu_{i}-u_{i t}-\eta_{i}
$$

Substituting $\theta(i, t)$ in (3) by (4) and (5) and rearranging obtains

$$
-\ln x_{1, i t}=\alpha(t)+\phi(t)^{\prime} \ln B_{i t}+\underbrace{\mu_{i}-u_{i t}-\eta i}_{\varepsilon_{i t}}+v_{i t}
$$

\footnotetext{
${ }^{23}$ The frontier concept is also applied in standard stochastic frontier models.
} 
with

$$
\varepsilon_{i t}=m_{i t}+v_{i t}=\mu_{i}-u_{i t}-\eta_{i}+v_{i t}
$$

denoting the composed error term. $\varepsilon_{i t}$ incorporates all potential deviation from the yearly frontier that is firm-specific.

Assuming a general Cobb-Douglas type stochastic input distance function, Equation 6 becomes

$$
\begin{aligned}
& -\ln x_{1, i t}=\alpha(t) \\
& +\sum_{p \in P_{\mid-p=1}} \beta_{p}(t) \ln \tilde{x}_{p, i t} \\
& +\sum_{q \in Q} \gamma_{q}(t) \ln y_{q, i t} \\
& +\sum_{k \in K} \delta_{k}(t) \ln z_{k, i t}+\underbrace{\mu_{i}-u_{i t}-\eta i}_{\varepsilon_{i t}}+v_{i t} .
\end{aligned}
$$

with the maximum annual intercept $\alpha(t)$, a noise term $v_{i t}$, firm fixed-effect $\mu_{i}$, persistent inefficiency $\eta_{i}$, and transient inefficiency $u_{i t}$. Applying this Cobb-Douglas specification to our data sample, the numeraire input becomes $x_{L, i t}$, the amount of hours worked. The right side of Equation 8 only has a single input ratio $x_{N, i t} / x_{L, i t}$ so that the first summation becomes trivial. The two outputs considered are $y_{C, i t}$ and $y_{E, i t}$, and the exogenous factors are $z_{D, i t}$ and $z_{O, i t}$.

Our estimation strategy to estimate the coefficients $\beta_{p}(t), \gamma_{q}(t), \delta_{k}(t)$ is explained in the Appendix A. The firm specific efficiencies are then determined from the estimated error terms $\hat{\eta}_{i}$ and $\hat{u}_{i t}$ : we differentiate between persistent and transitent efficiency. Persistent efficiency is calculated by $\mathrm{TE}_{\text {pers }, i}=\exp \left(-\hat{\eta}_{i}\right)$, transient efficiency $\mathrm{TE}_{\text {tran }, i t}=\exp \left(-\hat{u}_{i t}\right)$, and overall efficiency $\mathrm{TE}_{o v, i t}$ with $\mathrm{TE}_{\text {pers }, i} * \mathrm{TE}_{\text {tran,it }}$. Hence, the overall productive efficiency is always strictly smaller than $T E_{\text {pers }, i}$ and $T E_{\text {tran }, i t}$ except that at least one of them is equal to one. 


\section{Empirical Results}

\subsection{Interpretation of estimated slope coefficients}

Table 4 reports the estimated smoothed coefficients of the IDF separately for each year in the study period 2006-2012 24 and the levels of statistical significance obtained by wild bootstrap. In general, the estimated coefficients, and thus, the elasticities of the IDF, have the expected signs across the entire time, i.e. $\hat{\beta}_{N}(t)$ and $\hat{\delta}_{D}(t)$ are positive and and $\hat{\gamma}_{C}(t)$ and $\hat{\gamma}_{E}(t)$ are negative which supports our production model. ${ }^{25}$ The input coefficient $\hat{\beta}_{N}(t)$ differs significantly from zero in all years, whereas the output coefficients $\hat{\gamma}_{C}(t)$ and $\hat{\gamma}_{E}(t)$ are only statistically significant from 2010-2012. We reiterate that all technology parameters vary significantly over time, hence favoring a flexible semiparametric IDF that captures the transformations in the production process.

Table 4: Estimated coefficients of the input distance function

\begin{tabular}{cccccc}
\hline Year & $\hat{\beta}_{N}(t)$ & $\hat{\gamma}_{C}(t)$ & $\hat{\gamma}_{E}(t)$ & $\hat{\delta}_{D}(t)$ & $\hat{\delta}_{O}(t)$ \\
\hline 2006 & $0.4512^{*}$ & -0.0088 & -0.0029 & 0.0159 & 0.0139 \\
2007 & $0.5407^{*}$ & -0.0057 & -0.0065 & 0.0151 & $0.0391^{*}$ \\
2008 & $0.6531^{*}$ & -0.0035 & -0.0108 & 0.0125 & $0.0675^{*}$ \\
2009 & $0.7300^{*}$ & -0.0137 & $-0.0149^{*}$ & 0.0196 & $0.0480^{*}$ \\
2010 & $0.7705^{*}$ & $-0.0347^{*}$ & $-0.0166^{*}$ & $0.0367^{*}$ & -0.0085 \\
2011 & $0.8051^{*}$ & $-0.0653^{*}$ & $-0.0236^{*}$ & $0.0575^{*}$ & $-0.0419^{*}$ \\
2012 & $0.8393^{*}$ & $-0.1051^{*}$ & $-0.0410^{*}$ & $0.0783^{*}$ & $-0.0526^{*}$ \\
\hline \hline
\end{tabular}

Note: ${ }^{*}$ denotes the significance at the 10 percent level.

In addition to Table 4, Figure 1 shows that the estimated values of the input coefficient $\hat{\beta}_{N}(t)$ increases steadily from 0.45 in 2006 to 0.84 in $2012 .{ }^{26}$ This coefficient can be interpreted as the share of total costs associated with a network (Färe et al., 1993). Equivalently, $\hat{\beta}_{L}(t)=1-\hat{\beta}_{N}(t)$ is the share of total costs associated with labor input. In this context, our results indicate that since 2007, the cost share of a network exceeds the cost share of labor, hence reflecting the capital-intensity of the sector. The increasing cost share of network, relative to labor, indicates the ongoing expansion and modification of the network necessary to achieve Energiewende, the rise in decentralized generation, and the imposed connection of more renewables.

Figure 2 shows the development of the output coefficients over time. Both coefficients decrease, i.e. more labor is required when more output is produced. The output coefficients

\footnotetext{
${ }^{24}$ We estimate the smoothed coefficients non-parametrically using a bandwidth of 1.1281.

${ }^{25}$ Due to duality between the distance function and the cost function (Färe et al., 1993), the slope coefficient of the output is the first derivative of the distance function with respect to this output, which corresponds to the negative cost elasticity.

${ }^{26}$ The vertical lines in Figure 1 visualize the 90 percent confidence interval for the annual estimates of the slope coefficient. The same applies also to the vertical lines in Figure 2 and Figure 3.
} 
Figure 1: Input coefficient, $\hat{\beta}_{N}(t)$, over time

Network

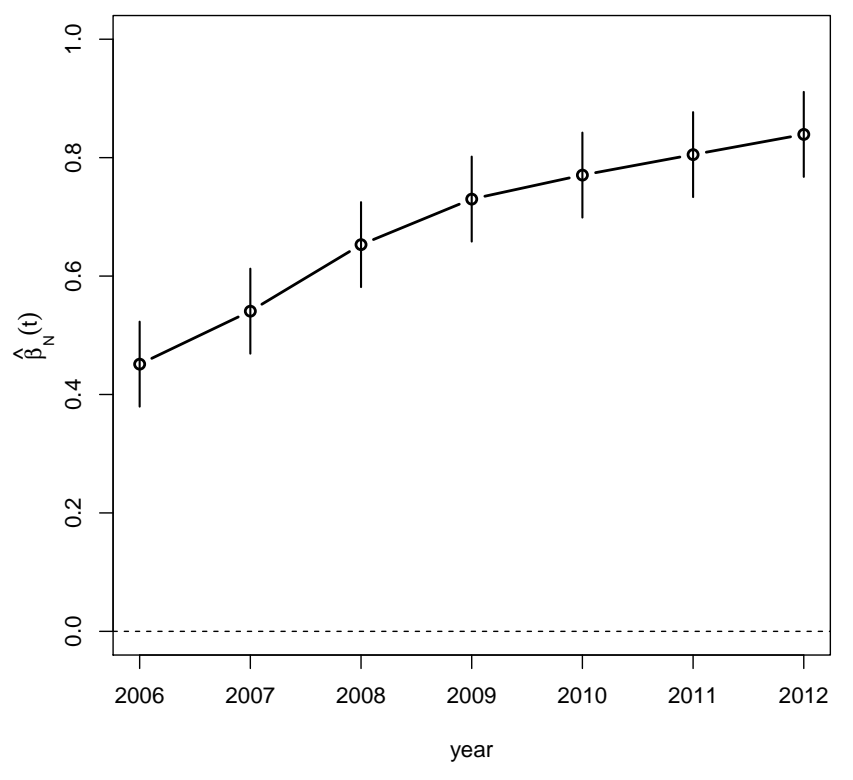

decreases after 2009, which coincides with the politically driven expansion of connecting more renewable energy. ${ }^{27}$ This finding indicates that operating the grid (producing additional output) becomes more costly due to more network complexity and the fluctuations caused by renewable sources. It is intuitive that $\hat{\gamma}_{C}(t)$ has a stronger affect on costs than $\hat{\gamma}_{E}(t)$, because it is more expensive to build new connections than to increase the distributed electricity through an existing grid. ${ }^{28}$

Figure 3 shows the development of the exogenous variables' coefficients during the study period. $\hat{\delta}_{D}(t)$ is positive, indicating that an increase in the customer density leads to a decrease in the amount of hours worked. A distribution grid serving a dense area requires less labor, is a commonly noted empirical result (Filippini and Wild, 2001). Comparing the left panels of Figures 2 and 3 reveals an interesting pattern of consumer density $\left(\hat{\delta}_{D}(t)\right)$, which is inversely related to the temporal progress of $\hat{\gamma}_{C}(t)$. One explanation is grid expansion and the associated increased cost of local renewable energy sources. It is also reasonable that network costs decrease due to increasing consumer density, whereas the expansion of renewable energy sources affects rural DSOs (Büchner et al., 2014). While the estimated coefficient $\hat{\delta}_{O}(t)$ indicates that overhead power lines are less costly

\footnotetext{
${ }^{27}$ While large power plants are normally connected to a transmission network, small-scale renewable energy sources are mostly connected to distribution grids. As pointed out in 3.1 the forced expansion of decentralized capacity of small-scale renewables adds to the cost elasticity of the consumers served.

${ }^{28}$ Connecting a customer to an electricity supply network implies that the grid needs to be expanded. The increase in fixed costs for installing new distribution lines far exceeds the variable costs for operation.
} 
Figure 2: output coefficients, $\hat{\gamma}_{C}(t)$ and $\hat{\gamma}_{E}(t)$, over time
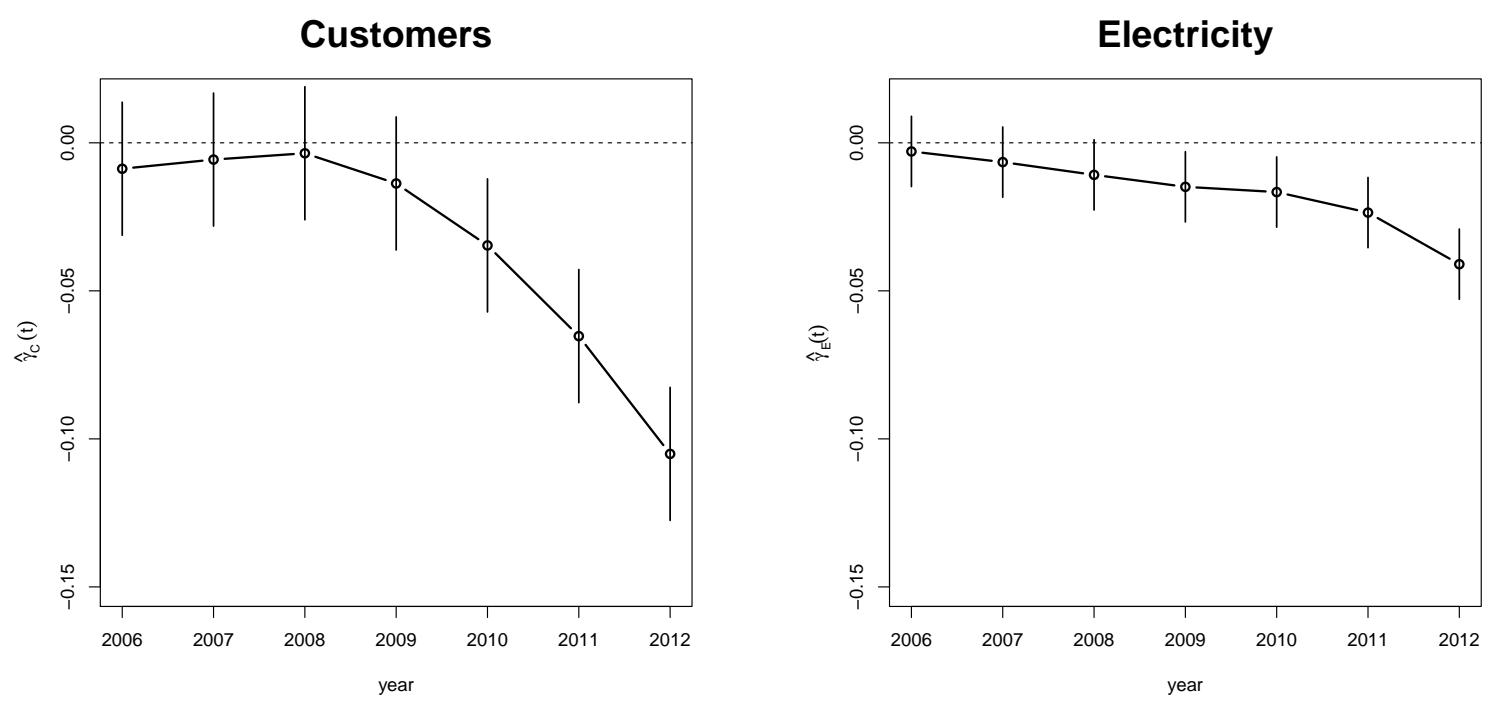

than underground cable from 2006 to 2009, they become more expensive in latter years.

\subsection{Analysis of efficiency scores}

Decomposing the firm-specific distance $\hat{m}_{i t}$ to the frontier, according to Equation 5, we derive time-varying, $\mathrm{TE}_{\text {tran }, i t}$, and persistent, $\mathrm{TE}_{\text {per }, i}$, efficiency estimates for every DSO. The results show very high, persistent efficiency scores throughout the sample which vary between 0.9964 and $0.9965 .^{29}$ Thus, the overall efficiency score follow the pattern of $T E_{\text {tran }, i t}$. We therefore focus on the time-varying efficiency.

Table 5 lists the summary statistics of the estimated transient efficiency scores, $T E_{\text {tran }, i t}$, by ownership type. In general, the efficiency estimates between 0.78 and 0.98 indicate a significant variance in performance levels between DSOs for public and private firms. In 2008 , the 25 percent quantile of private (state-owned) DSO has an efficiency of 0.8294 (0.8206), whereas the 75 percent qunatile of private (state-owned) DSO has an efficiency of 0.8819 (0.8728).

Table 5 also lists median efficiency scores between 0.80 and 0.90 over all years and ownership types. Looking at the ownership types separately, the median scores tend to increase slightly until 2009 and then stabilize. It is worth emphasizing that this is an expected finding, given that in Germany implemented a more efficiency-oriented regulatory scheme

\footnotetext{
${ }^{29}$ The values show the variation between the 25 and 75 percent quantile. Maximum and minimum persistent efficiency scores cannot be reported due to data privacy, which apply for the whole section. For convenience, we do not report all results in detail.
} 
Figure 3: Exogenous factor coefficients, $\hat{\delta}_{D}(t)$ and $\hat{\delta}_{O}(t)$, over time
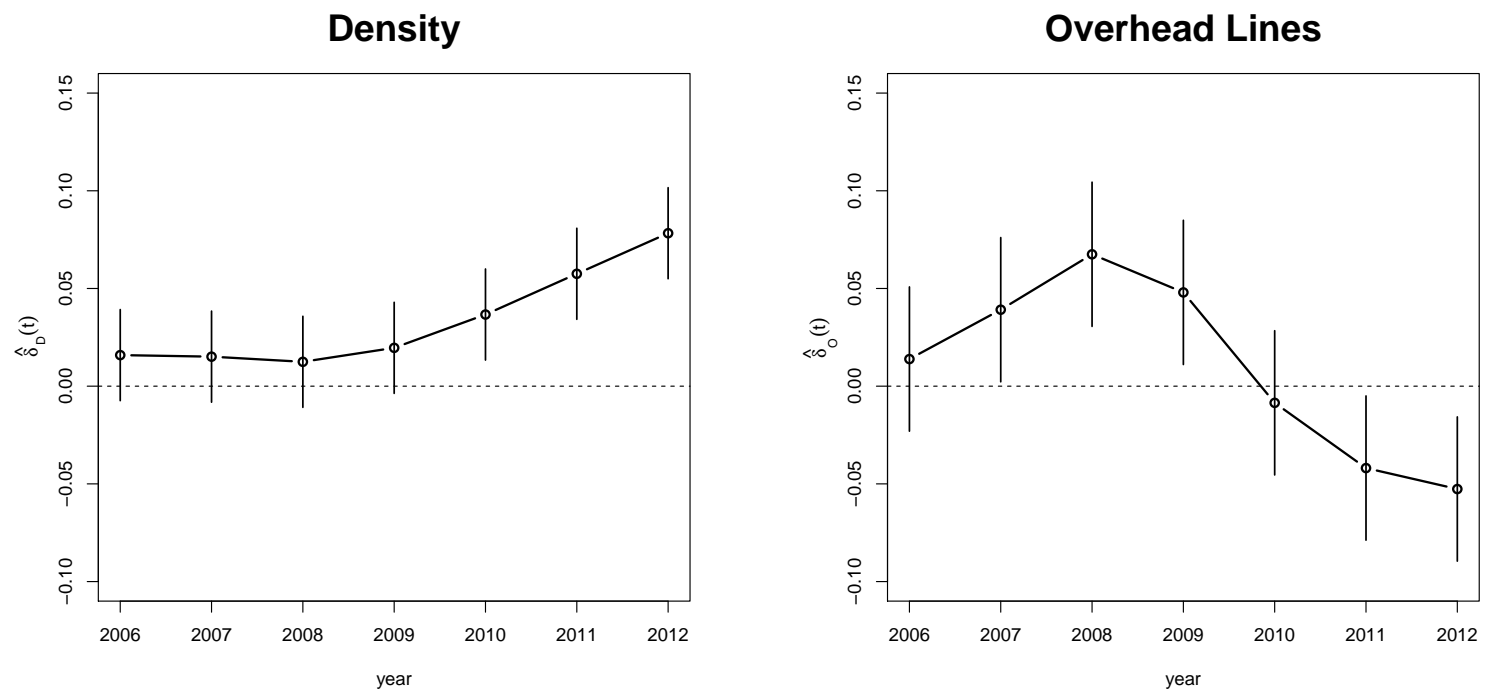

Table 5: Transient efficiency scores $T E_{\text {tran }, i t}=\exp \left(-u_{i t}\right)$

\begin{tabular}{llcccc}
\hline \hline Year & Type & $25 \%$ Quart. & Median & Mean & $75 \%$ Quart. \\
\hline \multirow{2}{*}{2006} & public & 0.7953 & 0.8248 & 0.8230 & 0.8631 \\
& private & 0.8758 & 0.8985 & 0.8744 & 0.9240 \\
2007 & public & 0.7777 & 0.8021 & 0.8090 & 0.8370 \\
& private & 0.8265 & 0.8627 & 0.8594 & 0.9150 \\
2008 & public & 0.8206 & 0.8445 & 0.8433 & 0.8728 \\
& private & 0.8294 & 0.8525 & 0.8535 & 0.8819 \\
2009 & public & 0.8820 & 0.8927 & 0.8931 & 0.9068 \\
& private & 0.8539 & 0.8788 & 0.8740 & 0.9097 \\
2010 & public & 0.8754 & 0.8895 & 0.8874 & 0.9039 \\
& private & 0.8613 & 0.8742 & 0.8706 & 0.8894 \\
2011 & public & 0.8716 & 0.8965 & 0.8873 & 0.9130 \\
& private & 0.8515 & 0.8702 & 0.8666 & 0.8855 \\
2012 & public & 0.8685 & 0.8956 & 0.8829 & 0.9144 \\
& private & 0.8244 & 0.8718 & 0.8527 & 0.8942 \\
\hline
\end{tabular}

in 2009. Comparing the median scores of private and state-owned DSOs reveals that public firms are on median less efficient before 2007, and catch up in 2008, whereas there is a negligible difference between the median scores of public and private firms after 2008 . We conclude that private and public firms perform on comparable efficiency levels. Comparing the mean efficiency scores reveals the same pattern. A formal Wilcoxon rank-sum test on average differences supports our conclusion. The Null hypothesis of this test is that the location shift between the group means is zero. With a $p$-value of 0.1919 we 
cannot reject the Null. Figure 4 shows the distributions of the transient efficiency scores for private (solid line) and public (dashed line) firms. The vertical lines represent the corresponding means of the distribution. Clearly, both mean values are almost identical. ${ }^{30}$ Hence, we find empirical evidence that DSOs of both ownership types perform equally efficiently and adapt equally well to the energy transition.

Figure 4: Distribution of the transient productive efficiency scores, public vs. private

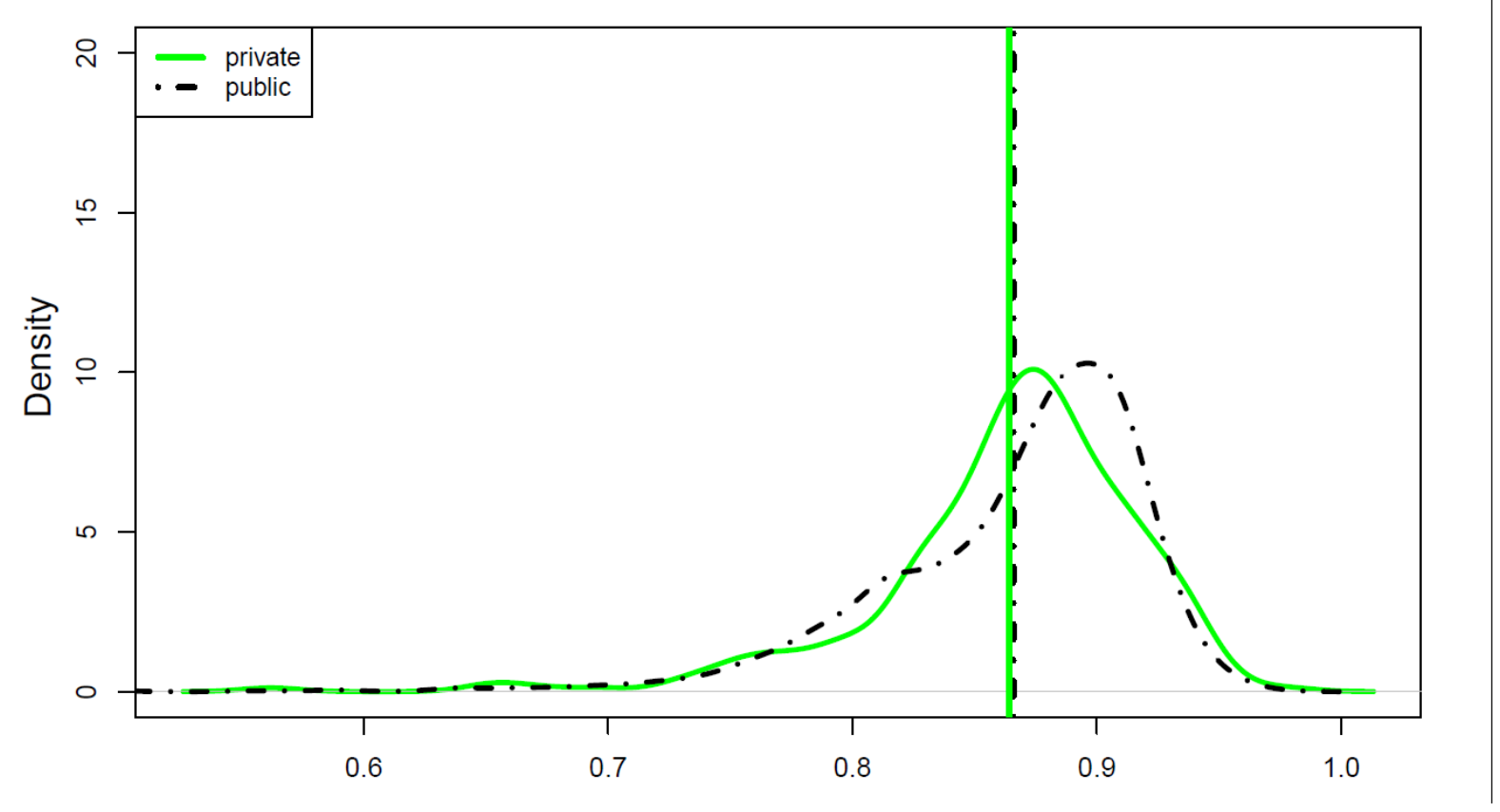

\subsection{Robustness Checks}

\subsubsection{Alternative estimators and specifications}

To validate our estimation results and underline the importance of our approach we compare our smoothed semiparametric slope coefficients with two alternative estimation procedures. First, we estimate the model as described in Section 5, but with coefficients that are independent of time. ${ }^{31}$ As Figure 5 shows, the slope coefficients obtained average between the time-varying semiparametric coefficients. ${ }^{32}$ While the slope estimates we obtained are reasonable, we conclude that an approach with fixed slope coefficients is not able to capture the technical progress taking place.

\footnotetext{
${ }^{30}$ Same applies when comparing the mean values of the overall productive efficiency scores. With a $p$-value of 0.1921 we cannot reject the Null hypothesis of the Wilcoxon rank-sum test either.

${ }^{31}$ Again, we follow the estimation strategy described in the Appendix A until Equation 10. Since the slope coefficients no longer depend on $t$, thei estimation becomes an OLS estimation.

${ }^{32}$ The time independet coefficients are all significantly different from zero on a 1 percent level except coefficient $\gamma_{2}$.
} 
Second, we estimate the specified production model using a pooled standard stochastic frontier model ${ }^{33}$ with and without firm effects. These estimation procedures allow us to compare our semi-parametric estimation to more common parametric procedures. Further, it allows comparing the slope coefficients in both time-dependent and timeindependent cases. Table 6, which records the obtained estimated values, shows that the signs of the slope coefficients are economically reasonable and in line with the findings from our semiparametric approach. The estimated values of $\hat{\beta}_{N}(t)$ remain similar. When comparing the estimates of the slope coefficients associated with the two outputs, $\hat{\gamma}_{C}(t)$ and $\hat{\gamma}_{E}(t)$, it is striking that only those coefficients obtained, including a firm effect, are similar to those of our semiparametric estimates. It seems that the values of the coefficients drop as soon as a firm effect is included regardless of whether we use a parametric or semiparametric model.

Table 6: Estimated coefficients of the input distance function using stochastic frontier model

\begin{tabular}{cccccc}
\hline Model & $\hat{\beta}_{N}(t)$ & $\hat{\gamma}_{C}(t)$ & $\hat{\gamma}_{E}(t)$ & $\hat{\delta}_{D}(t)$ & $\hat{\delta}_{O}(t)$ \\
\hline SFA without firm effect & $0.8958^{* * *}$ & $-0.4381^{* * *}$ & $-0.3019^{* * *}$ & $0.1538^{* * *}$ & $-0.0157^{*}$ \\
SFA with firm effect & $0.8979^{* * *}$ & -0.0120 & -0.0269 & 0.0289 & 0.0259 \\
\hline \hline Note:*** denotes a significance level smaller than 0.1 percent, ${ }^{*}$ denotes the significance \\
at the 5 percent level.
\end{tabular}

\subsubsection{Estimation with no change in ownership}

Since our original sample includes firms that change ownership over time, we perform the same analysis on a sample which only includes firms having the same ownership in each year of observation. This robustness check addresses the concern that possibly very efficient private (public) firms become publicly (privately) owned, and therefore, skew the results in favor of public (private) ownership.

Table 7 lists the values of the smoothed coefficients of the estimation excluding firms changing ownership. Comparing these results with those reported in Table 4 shows they only differ after the third decimal, the shape of this technical production frontier is very similar to the one estimated beforehand. Since the annual shape of the frontier changes very little, it is reasonable that the firm-specific efficiency scores also differ very little between the estimations.

Again, we find mostly efficient and inefficient firms among both state-owned and private ownership types. The persistent efficiency scores are always close to one and do not differ between ownership type. Transient efficiency scores are also close to the obtained results.

\footnotetext{
${ }^{33}$ More precisely, we use the estimator proposed by Battese and Coelli (1992).
} 
Table 7: Estimated coefficients of the input distance function, without ownership changers

\begin{tabular}{cccccc}
\hline Year & $\hat{\beta}_{N}(t)$ & $\hat{\gamma}_{C}(t)$ & $\hat{\gamma}_{E}(t)$ & $\hat{\delta}_{D}(t)$ & $\hat{\delta}_{O}(t)$ \\
\hline 2006 & $0.4567^{*}$ & -0.0081 & -0.0030 & 0.0158 & 0.0134 \\
2007 & $0.5458^{*}$ & -0.0047 & -0.0066 & 0.0146 & 0.0385 \\
2008 & $0.6585^{*}$ & -0.0028 & -0.0109 & 0.0117 & 0.0667 \\
2009 & $0.7350^{*}$ & -0.0135 & -0.0149 & 0.0192 & 0.0467 \\
2010 & $0.7742^{*}$ & -0.0347 & -0.0165 & 0.0368 & -0.0100 \\
2011 & $0.8094^{*}$ & $-0.0658^{*}$ & -0.0237 & 0.0581 & -0.0424 \\
2012 & $0.8452^{*}$ & $-0.1064^{*}$ & -0.0415 & $0.0794^{*}$ & $-0.0526^{*}$ \\
\hline \multicolumn{5}{l}{ Note: ${ }^{*}$ denotes the significance at the 10 percent level. }
\end{tabular}

The median values for public (private) firms ranges between 0.7997 and 0.895 (0.8494 and 0.9022). While the median of publicly owned firms lags slightly in terms of productive efficiency until 2008, they catch up later. The Wilcxon rank-sum test with continuity confirms the result given in Section 6.2 and does not reject the Null with a $p$-value of 0.3434. Hence, we rebut the argument that firms changing ownership over time influence the results of this study.

\section{Conclusion}

Against the background of the ongoing policy debate on ownership in the energy sector, this paper aimed to understand the performance differences between publicly and privately owned firms in a sector experiencing significant restructuring. A semiparametric input distance function model, flexible enough to account for the required changes in technology and the decomposition of efficiency across ownership type, was proposed. The model was validated with a rich panel data set of 1897 observations of Germany's public and private electricity distribution firms operating between 2006 and 2012. The results showed that the DSOs' production frontier changed shape over time, clearly indicating that firms adapted their technology in response to Energiewende. There was no empirical evidence that public firms operated any less efficiently than private firms.

\section{Acknowledgements}

This research which is part of the project 'Municipal infrastructure companies against the background of energy policy and demographic change (KOMIED)' was funded by the Leibniz Commission (SAW-2013-DIW-5). The paper was presented at the North Americal Workshop on Productivity Analysis 2016 (NAPW), the Lunch Seminar at University Neuchatel, the 43rd Annual Conference of the European Association for Research 
in Industrial Economics (EARIE) and the Jahrestagung des Vereins für Sozialpolitik 2016 (VfS). We gratefully acknowledge Pio Baake, Tomaso Duso, and Christian von Hirschhausen for their valuable comments and suggestions and Ann Stewart for language assistance. The usual disclaimer applies. 
Figure 5: Comparison of slope coefficient, with and without time trend
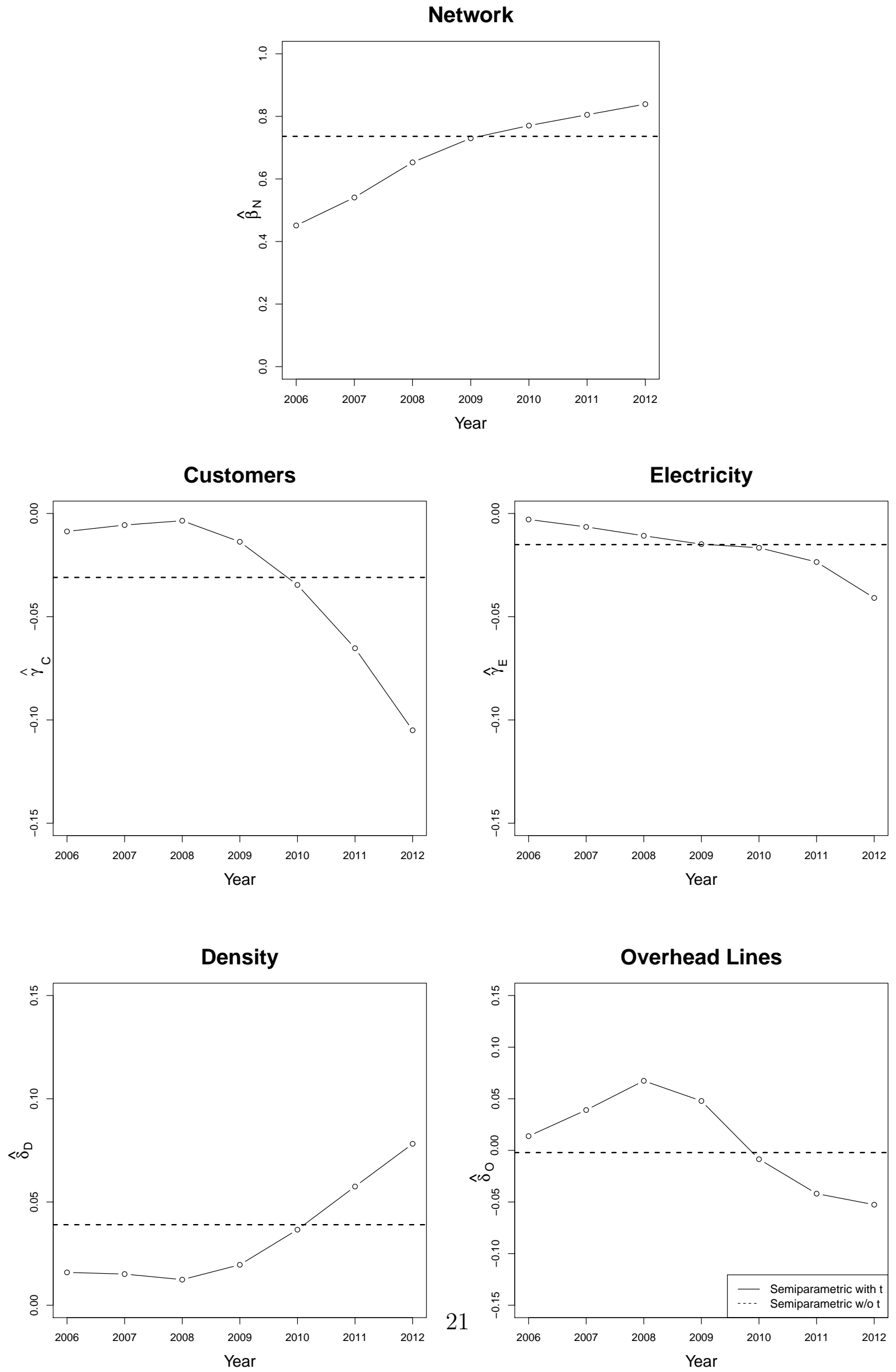


\section{Bibliography}

Alchian, A., Demsetz, H., 1973. The property right paradigm. The Journal of Economic History 33 (1), 16-27.

Arbeitsgemeinschaft Energiebilanzen, 2016. Auswertungstabellen zur Energiebilanz Deutschland 1990 bis 2015. Tech. rep.

URL http://www.ag-energiebilanzen.de/10-0-auswertungstabellen.html

Atkinson, S. E., Halvorsen, R., 1986. The relative efficiency of public and private firms in a regulated environment: The case of us electric utilities. Journal of Public Economics 29 (3), 281-294.

Bartel, A. P., Harrison, A. E., 2005. Ownership versus environment: Disentangling the sources of public sector inefficiency. The Review of Economics and Statistics 87 (1), $135-147$.

Berlin Energie, 2016. Stromnetz zurück zur Stadt - Abgabe indikatives Angebot.

URL http://www.berlinenergie.de/abgabe-indikatives-angebot-fuer-eine -vollstaendige-rekommunalisierung-des-berliner-stromnetzes-2/

Berlo, K., Wagner, O., 2013. Stadtwerke - Neugründungen und Rekommunalisierungen: Energieversorgung in kommunaler Verantwortung: Bewertung der 10 wichtigsten Ziele und deren Erreichbarkeit. Wuppertal Institut für Klima, Umwelt, Energie GmbH.

Borghi, E., Del Bo, C., Florio, M., 2016. Institutions and firm's productivity: Evidence from electricity distribution in the eu. Oxford Bulletin of Economics and Statistics 78 (2), 170-196.

Boylan, R. T., 2016. Power to the people: Does ownership type influence electricity service? Journal of Law \& Economice 59, 441-476.

Brüggemeier, F.-J., 2015. Sonne, Wasser, Wind: Die Entwicklung der Energiewende in Deutschland. Friedrich-Ebert-Stiftung.

URL http://library.fes.de/pdf-files/wiso/11579.pdf

Büchner, J., Katzfey, J., Flörcken, O., Moser, A., Schuster, H., Dierkes, S., Van Leeuwen, T., Verheggen, L., Uslar, M., van Amelsvoort, M., 2014. Moderne Verteilernetze für Deutschland (Verteilernetzstudie).

URL http://www.bmwi.de/BMWi/Redaktion/PDF/Publikationen/Studien/ verteilernetzstudie, property=pdf, berei $c h=b m w i 2012$, sprache=de, rwb=true . pdf 
Bundesministerium für Wirtschaft und Energie, 2016. Erneuerbare Energien in Zahlen Nationale und internationale Entwicklung im Jahr 2015.

URL http://www.bmwi.de/BMWi/Redaktion/PDF/E/erneuerbare-energien-in -zahlen, property=pdf, bereich=bmwi2012, sprache=de, rwb=true.pdf

Bundesnetzagentur, 2014. Monitoringbericht 2014. Tech. rep., Bundesnetzagentur. URL https : //www . bundesnetzagentur. de/SharedDocs/Downloads/DE/Allgemeines /Bundesnetzagentur/Publikationen/Berichte/2014/Monitoringbericht_2014 _BF.pdf\%3F__blob\%3DpublicationFile\%26v\%3D3

Button, K. J., Weyman-Jones, T. G., 1994. X-efficiency and technical efficiency. Public Choice 80, 83-104.

Cullmann, A., 2010. Benchmarking and firm heterogeneity: a latent class analysis for German electricity distribution companies. Empirical Economics 42 (1), 147-169.

Das, A., Kumbhakar, S. C., 2012. Productivity and efficiency dynmaics in indian banking: an input distance function approach incorporating quality of inputs and outputs. Journal of Applied Econometrics 27 (2), 205-234.

De Alessi, L., 1974. Mangerial tenure under private and government ownership in the electric power industry. Journal of Political Economy 82 (3), 645-653.

Demsetz, H., 1967. Toward a theory of property rights. American Economic Review 57, 347-359.

Deutsche Energie-Agentur, 2012. Ausbau- und Innovationsbedarf der Stromverteilnetze in Deutschland bis 2030. Tech. rep., Berlin.

URL https://shop.dena.de/fileadmin/denashop/media/Downloads_Dateien/esd /9100_dena-Verteilnetzstudie_Abschlussbericht.pdf

Färe, R., Grosskopf, S., Lovell, C. A. K., Yaisawarng, S., 1993. Derivation of shadow prices for undesirable outputs: A distance function approach. The Review of Economics and Statistics 75 (2), pp. 374-380.

Färe, R., Primont, D., 1995. Multi-output production: theory and applications. Kluwer.

Filippini, M., Wild, J., 2001. Regional differences in electricity distribution costs and their consequences for yardstick regulation of access prices. Energy Economics 23 (4), 477-488.

Hart, O. D., 1983. The market mechanism as an incentive scheme. The Bell Journal of Economics, 366-382. 
Jamasb, T., Pollitt, M., 2000. Benchmarking and regulation: international electricity experience. Utilities Policy 9 (3), 107-130.

Jondrow, J., Lovell, C. K., Materov, I. S., Schmidt, P., 1982. On the estimation of technical inefficiency in the stochastic frontier production function model. Journal of econometrics 19 (2), 233-238.

Kumbhakar, S. C., Hjalmarsson, L., 1998. Relative performance of public and private ownership under yardstick competition: electricity retail distribution. European Economic Review 42 (1), 97-122.

Kumbhakar, S. C., Sun, 2012. Estimation of tfp growth: a semiparametric smooth coefficient approach. Empirical Economics 43 (1), 1-24.

Kwoka, J. E., 2005. The comparative advantage of public ownership: Evidence from US electric utilities. Canadian Journal of Economics/Revue canadienne d'économique $38(2), 622-640$.

Laffont, J.-J., Tirole, J., 1991. Privatization and incentives. Journal of Law, Economics, \& Organization, 84-105.

Laffont, J.-J., Tirole, J., 1993. A theory of incentives in procurement and regulation. MIT press.

Leibenstein, H., 1966. Allocative efficiency vs." x-efficiency". The American Economic Review, 392-415.

Megginson, W. \& Netter, J., 2001. From state to market: A survey on empirical studies on privatization. Journal of Economic Literature 39, 321-389.

Monopolkommission, 2014. Hauptgutachten XX: Eine Wettbewerbsordnung für die Finanzmärkte - Kapitel V: Kommunale Wirtschaftstätigkeit und der Trend zur Rekommunalisierung. Bonn.

URL http://www . monopolkommission.de/index .php/de/homepage/82-gutachten/ hauptgutachten/271-hauptgutachten-xx

Neuberg, L., 1977. Two issues in the municipal ownership of electric power distribution systems. Bell Journal of Economics 8 (1), 303-323.

Peltzman, S., 1971. Pricing in public and private enterprises: Electric utilities in the united states. Journal of Law and Economics 14 (1), 109-147. 
Peters, L., 1993. Non-profit electric utilities in the united states: Pricing and efficiency. Annals of Public and Cooperative Economics 64 (4), 575-604.

Pollitt, M., 1995. Ownership and Performance in Electric Utilities: The International Evidence on Privatization and Efficiency. Oxford University Press.

Robinson, P. M., 1989. Nonparametric estimation of time-varying parameters. In: Statistical Analysis and Forecasting of Economic Structural Change. Springer, pp. 253-264.

Rose, N., Joskow, P., 1990. The diffusion of new technologies: Evidence from the electric utility industry. RAND Journal of Economics 21 (3), 354-373.

Shephard, R. W., 1953. Cost and production functions. Princeton University Press.

Shirley, M. M., Walsh, P., 2001. Public vs. private ownership: the current state of the debate. World Bank Policy Research Working Paper (2420).

Shleifer, A., Vishny, R. W., 1994. Politicians and firms. The Quarterly Journal of Economics, 995-1025.

Sun, K., Kumbhakar, S. C., Tveterås, R., 2015. Productivity and efficiency estimation: A semiparametric stochastic cost frontier approach. European Journal of Operational Research 245 (1), 194-202.

Villalonga, B., 2000. Privatization and efficiency: differentiating ownership effects from political, organizational, and dynamic effects. Journal of Economic Behavior \& Organization $42(1), 43-74$.

Vining, A. R., Boardman, A. E., 1992. Ownership versus competition: Efficiency in public enterprise. Public choice 73 (2), 205-239. 


\section{A Estimation Strategy}

We estimate Equation 3 with 4 in a two-step approach based on Sun et al. (2015). ${ }^{34}$ In the first step, we estimate the slope coefficients and intercept of the input distance function. In the second step we identify the two inefficiency components by making distributional assumptions on the inefficiency components and on the random firm-effect. ${ }^{35}$

\section{A.1 Step1: Estimation of slopes and intercept}

Assuming a Cobb-Douglas type stochastic input distance function and inserting the varaibles from our dataset, Equation 3 becomes

$$
\begin{aligned}
-\ln x_{L, i t} & =\theta(i, t) \\
& +\beta_{N}(t) \ln \left(\tilde{x}_{N, i t}\right) \\
& +\gamma_{C}(t) \ln \left(y_{C, i t}\right)+\gamma_{E}(t) \ln \left(y_{E, i t}\right) \\
& +\delta_{D}(t) \ln \left(z_{D, i t}\right)+\delta_{O}(t) \ln \left(z_{O, i t}\right)+v_{i t} .
\end{aligned}
$$

For estimation reasons, we only estimate the frontier with its time-varying slope coefficients, but without intercept. We apply the Robinson type transformation (Robinson, 1989) and rewrite Equation 9 as:

$$
\begin{aligned}
-\ln x_{L, i t}^{*} & =\beta_{N}(t) \ln \left(\tilde{x}_{N, i t}^{*}\right) \\
& +\gamma_{C}(t) \ln \left(y_{C, i t}^{*}\right)+\gamma_{E}(t) \ln \left(y_{E, i t}^{*}\right) \\
& +\delta_{D}(t) \ln \left(z_{D, i t}^{*}\right)+\delta_{O}(t) \ln \left(z_{O, i t}^{*}\right)+v_{i t} .
\end{aligned}
$$

where, for estimation purposes, the expected conditional mean of each variable is subtracted from the original variable's values, i.e., $\ln \left(x_{L, i t}^{*}\right)=\ln \left(x_{L, i t}\right)-E\left(\ln \left(x_{L, i t}\right) \mid i, t\right)$, $\ln \left(\tilde{x}_{N, i t}^{*}\right)=\ln \left(\tilde{x}_{N, i t}\right)-E\left(\ln \left(\tilde{x}_{N, i t}\right) \mid i, t\right), \ln \left(y_{q, i t}^{*}\right)=\ln \left(y_{q, i t}\right)-E\left(\ln \left(y_{q, i t}\right) \mid i, t\right) \forall q \in\{C, E\}$, and $\ln \left(z_{k, i t}^{*}\right)=\ln \left(z_{k, i t}\right)-E\left(\ln \left(z_{k, i t}\right) \mid i, t\right) \forall k \in\{D, O\}$.

To estimate the conditional expectations $E\left(\ln \left(x_{L, i t}\right) \mid i, t\right)$ and $E\left(\ln \left(B_{i t}\right) \mid i, t\right)$ we apply the nonparametric Nadaraya-Watson kernel estimator used in Sun et al. (2015). The es-

\footnotetext{
${ }^{34}$ While Sun et al. (2015) used the semiparametric smooth coefficient model to estimate a cost function we adapted to estimate an IDF.

${ }^{35}$ This approach could also be extended to describe firms' productivity changes and the possible causes.
} 
timation of Equation 10 follows the estimation strategy of a semi-parametric smooth coefficients model without intercept (Sun et al., 2015) and provides the nonparametric functions of the slope coefficients, i.e. $\hat{\beta}_{N}(t), \hat{\gamma}_{C}(t), \hat{\gamma}_{E}(t), \hat{\delta}_{D}(t)$ and $\hat{\delta}_{O}(t)$.

To estimate the intercept, $\theta(i, t)$, in Equation 9, we compute the residuals, $\hat{\omega}_{i t}$, of the estimated distance function using the observed left and right side variables, $\ln x_{L, i t}$, $\ln y_{q, i t} \forall q \in\{C, E\}$, and $\ln z_{k, i t} \forall k \in\{D, O\}$, and the estimated coefficients as

$$
\begin{aligned}
\hat{\omega}_{i t}= & -\ln x_{L, i t}-\hat{\beta}_{N}(t) \ln \left(\tilde{x}_{N, i t}\right) \\
& -\sum_{q \in Q} \hat{\gamma}_{q}(t) \ln \left(y_{q, i t}\right) \\
& -\sum_{k \in K} \hat{\delta}_{k}(t) \ln \left(z_{k, i t}\right) .
\end{aligned}
$$

The residual term $\hat{\omega}_{i t}$ consists of an intercept and a noise term, i.e., $\hat{\omega}_{i t}=\theta(i, t)+v_{i t}$. The best predictor for $\theta(i, t)$ is its conditional mean $E\left(\omega_{i t} \mid i, t\right)$, under the assumption that the noise term $v_{i t}$ is uncorrelated with the intercept and has a zero conditional mean, i.e., $E\left(v_{i t} \mid i, t\right)=0$. Again, we use the Nadaraya-Watson kernel estimator to estimate $E\left(\hat{\omega}_{i t} \mid i, t\right)$. Using the predicted values of $\theta(i, t)$, i.e. $\hat{\theta}(i, t)$, and Equation 4 , we obtain $\hat{\alpha}(t)$ as the annual maximum observed $\hat{\theta}(i, t)$ and $\hat{m}_{i t}$ which we interpret as distance from an observation to the estimated IDF due to inefficiency and firm effect.

\section{A.2 Step 2: Decomposing inefficiency}

According to Equation 5, we want to decompose the total distance $\hat{m}_{i t}$ into three components: persistent and time-varying inefficiency, and a firm effect. We can also interpret firm effect $\eta_{i}$ as unobserved heterogeneity which is constant over time and cannot be influenced by the firms. Thus, we aim to separate it from inefficiency. For estimation purposes, however, we use the overall deviation from the IDF, i.e., $\hat{\varepsilon}_{i t}$ obtained by adding $\hat{m}_{i t}$ and $\hat{v}_{i t}$ following Equation 7.

To decompose Equation 7 empirically, we re-define $\varepsilon_{i t}$ as:

$$
\varepsilon_{i t}=a_{0}+\psi_{i}+\chi_{i t}
$$

where $a_{0}$ is an intercept which is time-invariant and the same across all observations and captures the expected means of each of the components shown in Equation 7, i.e., $a_{0}=E\left[v_{i t}\right]+E\left[\mu_{i}\right]+E\left[-u_{i t}\right]+E\left[-\eta_{i}\right]$. Assuming that noise $v_{i t}$ and firm effects $\mu_{i}$ are variables of zero mean, yields to $a_{0}=E\left[-u_{i t}\right]+E\left[-\eta_{i}\right]$. Further, $\psi_{i}$ captures all time-invariant observation-specific components in Equation 7 and is defined as $\psi_{i}=$ 
$\mu_{i}-\left[\eta_{i}+E\left[-\eta_{i}\right]\right]=\mu_{i}-\eta_{i}-E\left[-\eta_{i}\right] . \chi_{i t}$ captures instead all time-varying observationspecific effects and is given by $\chi_{i t}=v_{i t}-\left[u_{i t}+E\left[-u_{i t}\right]=v_{i t}-u_{i t}-E\left[-u_{i t}\right]\right.$.

Random firm effects $\psi_{i}$ represents a firm-specific fixed effect entered explicitly in the model. To obtain an estimate of the firm effects, we introduce firm-specific dummy variables $d_{i}$ that becomes 1 , if firm $i$ is observed in the year $t$ considered.

Hence, Equation 12 becomes

$$
\varepsilon_{i t}=a_{0}+\sum_{j=1}^{N} \psi_{i} d_{j}+\chi_{i t}
$$

where index $j$ is an alias of index $i$. We estimate the model using ordinary least squares (OLS) where the dependent variable $\varepsilon_{i t}$ is substituted by $\hat{\varepsilon}_{i t}=\hat{m}_{i t}+\hat{v}_{i t}$. From that we obtain $\hat{\psi}_{i 0}$ and $\hat{\chi}_{i t}$.

Persistent inefficiency $\eta_{i}$, is part of the firm effect $\psi_{i}$. Since $\psi_{i}:=\mu_{i}+\left[\eta_{i}-E\left(\eta_{i}\right)\right]$ and $b_{0}=-E\left[-\eta_{i}\right]$, we can write

$$
\psi_{i}=b_{0}+\mu_{i}-\eta_{i}
$$

We use the typical stochastic frontier approach for production functions, where $b_{0}$ represents the constant term, $\mu_{i}$, the i.i.d. persistent noise term (firm effect) and $\eta_{i}$ represents half normally distributed noise, i.e., persistent inefficiency. We estimate the model by substituting $\psi_{i}$ with $\hat{\psi}_{i}$ obtained from Equation 13 and determine the persistent $\mathrm{TE}_{p e r s, i}$ following Jondrow et al. (1982) as $E\left(-\hat{\eta}_{i} \mid r_{i}\right)$, with $r_{i}=\hat{\mu}_{i}+\hat{\eta}_{i}$.

Transient inefficiency Similar to determining persistent inefficiency estimates, we use the definition $\chi_{i t}=v_{i t}+\left[u_{i t}-E\left(u_{i t}\right)\right]$ and write

$$
\chi_{i t}=c_{0}+v_{i t}-u_{i t}
$$

with the intercept $c_{0}=-E\left(-u_{i t}\right) . \quad u_{i t}$ follows a half normal distribution representing the inefficiency term, and $v_{i t}$, normally distributed term with zero mean, accounts for noise. To estimate Equation 15, we replace $\chi_{i t}$ by its estimate $\hat{\chi}_{i t}$. Again, we determine time-varying inefficiency, $\mathrm{TE}_{\text {tran }, i t}$ by computing $E\left(-\hat{u}_{i t} \mid s_{i t}\right)$ (Jondrow et al., 1982). $s_{i t}$ describes the complete residual term, which is composed of $\hat{u}_{i t}+\hat{v}_{i t}$. 